\title{
Effect of Production Factors on the Development of Colorectal Cancer in the Population of the Omsk Region
}

\author{
NG Shirlina* and AS Kolchin \\ Department of Epidemiology, Omsk State Medical University, Russia \\ *Corresponding author: NG Shirlina, Osmu, Department of Epidemiology, Omsk State Medical University, Russia
}

To Cite This Article: NG Shirlina. Effect of Production Factors on the Development of Colorectal Cancer in the Population of the Omsk Region. Am J Biomed Sci \& Res. 2019 - 3(6). AJBSR.MS.ID.000736. DOI: 10.34297/AJBSR.2019.03.000736

Received: June 21, 2019 | Published: July 11, 2019

\section{Short Communication}

The data of an epidemiological analytical study (case-control) are presented, in which 609 people living in the Omsk Region took part. The prevalence of colorectal cancer risk factors associated with production factors in the population of the Omsk Region was studied.

Keywords: Colorectal cancer; Risk factors associated with working conditions; Omsk region

Malignant neoplasms are the second most frequent and socially significant cause of mortality after cardiovascular diseases, which forms a negative demographic balance in our country [1]. In the structure of the malignant neoplasms of the gastrointestinal tract, colorectal cancer (CRC) takes the 3rd place in terms of the incidence of morbidity and the 2nd place in terms of mortality [2]. For a long time, the statistics on the incidence of occupational CRC in our country did not correspond to reality. The reason for the development of professional CRC are somatic mutations that occur under the influence of various (mostly chemical) carcinogens. In addition, the professional cancer of this localization is affected by specialists who receive increased doses of ionizing radiation, and people working outdoors, in conditions of excessive insolation, noise, high humidity and low temperatures [3].

\section{Research Objectives}

Assess the prevalence and significance of factors related to working conditions in the development of CRC in the urban and rural population of the Omsk region.

\section{Materials and Methods}

In 2016-2017 An epidemiological analytical study (casecontrol) was conducted, in which 609 people took part - residents of the Omsk region aged 30 to 85 years (average age 51.2 years; $95 \%$ CI $48.1 \div 54.3$ ). The criteria for inclusion in the first group (people with $\mathrm{CRC}-\mathrm{n}=53$ ) were permanent residence in the study area of 10 or more years, age from 30 to 85 years, diagnosis of CRC, obtaining consent for inclusion in the study and personal data processing. The second group was formed from respondents without CRC $(\mathrm{n}=556)$ who have been living in the study area for 10 or more years, aged 30 to 85 years, who agreed to be included in the study and to process personal data. The study examined 12 factors characterizing the conditions of professional activity of the study participants: non-ionizing radiation, noise, microclimate, contact with chemicals, antibiotics and allergens, biological factor, neuro-emotional stress, the severity of the labor process, work in night shifts, light environment. All studied factors were attributed to correctable. The survey respondents were sampled through a direct questionnaire. After explaining to the respondents, the goals and objectives of the survey, the questionnaire was filled in by the respondent independently. The significance of the factors was estimated by the odds ratio indicator with a 95\% confidence interval (CI). Data analysis was performed using STATISTICA 6.0, Neurocomp, Microsoft Office Excel.

\section{Results and Discussion}

The most common factors studied in the population with CRC were: neuro-emotional tension (62.7\%), the presence of a biological factor (52.8\%). Neuro-emotional tensions and noise at the workplace prevailed in the second group studied (45.5 and $35.1 \%$, respectively). Of the 12 risk factors for CRC associated with working conditions, for residents of the Omsk Region only one confirmed its importance (the biological factor). On seven factors, no differences between the groups were found, and on four other factors - the influence of noise, work in night shifts, low illumination, and also on the characteristics of physical activity revealed a "paradoxical" situation, expressed in their more frequent identification in the group of healthy respondents. The residents of the regional center (Omsk), participants in the study, differences between groups were identified by five of the studied factors related to working conditions: microclimate, biological factor, neuro-emotional tension, work in night shifts and in low light conditions. For urban residents, they confirmed their importance as factors contributing to the development of CRC: microclimate, 
biological factor, and neuro-emotional tension. On seven factors, differences between groups were not found, and two factors related to working conditions and the risk of CRC were detected more often in the group of healthy respondents.

In rural residents, participants in the study, differences were identified in six of the 12 risk factors for CRC associated with working conditions: noise, microclimate, chemicals, biological factors, the severity of the labor process, contact with antibiotics and allergens. For this group of respondents, only two risk factors for CRC confirmed their significance, related to the conditions of the labor process and the working environment - the presence of chemicals and the influence of biological factors. By six factors, differences in the groups were not detected, but by four factors (noise from the microclimate, severity of the labor process, contact with antibiotics and allergens) they were found to be more frequent in the group of healthy participants. The etiological share (ES) of the biological risk factor in the development of CRC on the territory of the Omsk Region was $70.8 \%$, which corresponds to a very high degree of professional conditionality. The following factors showed the average degree of professional conditionality: chemical substances ( $\mathrm{p}<0.01$; OR, 2.06, 95\% CI, $0.58 \div 6.27$; ED-47.5\%), microclimate ( $\mathrm{p}<0.01$; OR 2.15, 95\% CI $0.98 \div 3.26$, ED-44.1\%), non-ionizing radiation ( $\mathrm{p}<0.01$; OR 1.86 , 95\% CI $0.48 \div 6.23$, ED$42.5 \%$ ), the severity of the labor process ( $p<0.01$; ORH $1.84,95 \%$ CI $0.75 \div 3.66$, ED-39.8\%), neuro-emotional tension ( $p<0.01$ ORH
2.37, 95\% CI $1.09 \div 2.09$, ED-33.8\%). The remaining factors had little or no degree of professional conditionality. Thus, the role of factors associated with the labor process in increasing the risk of CRC in the region has been established, which is consistent with the literature [1,4] and has determined their importance in building oversight and primary prevention programs through the correction of working conditions. The paradox of the distribution, as well as the absence of the influence of a number of factors on the risk of CRC, can be explained by regional characteristics and sample characteristics. Findings Among the population of the Omsk region, the leading risk factor for CRC associated with working conditions is the biological factor. At the same time, factors that did not confirm their significance were the influence of noise, work in night shifts, low illumination, and also the characteristic of physical activity. For residents of the regional center, the leading risk factors for CRC related to working conditions were microclimate, biological factor, neuro-emotional tensions, and for respondents living in rural areas the presence of chemicals and the influence of biological factors.

\section{References}

1. World Cancer Report 2014 resource.

2. Kaprina, VV Starinsky, GV (2017) Petrova Malignant neoplasms in Russia in 2015 (morbidity and mortality) Moscow, Russia p. 19.

3. Chan AT (2010) Primary prevention of colorectal cancer . Gastroenterology 6: 2029-2043. 